\title{
O Marxismo na História da Psicologia: Um estudo no periódico Mnemosine
}

\author{
Marxism in the History of Psychology: A study on the journal Mnemosine
}

\author{
Lucas Matheus Pereira Cruvinel; Fernando Lacerda Junior \\ Pontifícia Universidade Católica de São Paulo; Universidade Federal de Goiás
}

\section{RESUMO:}

O presente trabalho apresenta pesquisa que explorou como o Marxismo foi apropriado por historiadoras e historiadores da Psicologia por meio de uma análise de artigos publicados na revista Mnemosine entre 2004 e 2016. O estudo buscou: (a) identificar que vertentes do Marxismo e autores foram utilizados em trabalhos que se apropriaram da tradição marxista; (b) classificar a forma pela qual o Marxismo é utilizado pelos historiadores da Psicologia. Foram analisados 42 artigos encontrados por meio das palavras-chave "Marx", "marxismo", "marxista" e "materialismo". A análise ocorreu em duas etapas e concluiu-se que o marxismo aparece em trabalhos que: (a) criticaram a concepção marxista de história; (b) identificaram o marxismo como fundamento de autores, publicações, escolas e tradições teóricas; (c) realizaram análises críticas de processos psicossociais no capitalismo. Não foram encontrados estudos que utilizam a concepção marxista de história para guiar modos de se fazer e pensar a História da Psicologia. Financiamento: CNPq.

Palavras-chave: Marxismo; Psicologia; História da Psicologia

\section{ABSTRACT:}

This paper presents a study on how Marxism was appropriated in the field of History of Psychology through a bibliographical research in the Journal Mnemosine. The objectives were: (a) to identify which trends and authors of Marxism were appropriated; (b) to classify the way that Marxism guides researches in History of Psychology. Through a survey using the keywords "Marx", "Marxism", "Marxist" and "materialism" were found 42 articles. The analysis demonstrated that the published articles presented: (a) critiques of Marxist conception of history; (b) studies that identified Marxism as a theoretical basis of specific author, paper, schools and traditions of thought; (c) critiques of psychosocial processes in capitalism. No studies were found using the Marxist conception of history in theoretical-methodological assumptions of History of Psychology. Support: CNPq.

Key-words: Marxism; Psychology; History of Psychology

DOI: 10.12957/mnemosine.2020.57675

\section{Introdução}

A máxima de que "tudo é história" certamente está presente na tradição marxista. Em Marx, a historicidade não é mais uma variável, mas um "princípio do próprio ser" (LUKÁCS, 1976/2012: 341). Por isso, há uma forte ênfase nas investigações históricas, pois somente assim o desenvolvimento de uma sociedade e as transformações sociais podem ser compreendidos 
(HOBSBAWM, 2013). Esta compreensão coincide com a tese de que o pensamento marxiano ${ }^{1}$ foi marcado pelo estudo da gênese, do movimento, das crises e das possibilidades de superação do capitalismo. Estudo que exigiu uma concepção histórico-social de indivíduo e a superação de concepções teleológicas de história (NETTO, 1985; 2011).

Teses como a determinação econômica, a relação dialética entre base e superestrutura, o atravessamento de interesses sociais (especialmente os interesses de classes) inclusive sobre o fazer científico, diferenciação ontológica entre natureza e sociedade, assim como o papel do indivíduo na história e uma concepção totalizante foram elementos da tradição marxista que influenciaram enormemente a historiografia (HOBSBAWM, 2013).

Todavia, na pesquisa historiográfica da Psicologia o marxismo é uma perspectiva pouco explorada. Ainda que existam estudos que destaquem contribuições teórico-metodológicas da tradição marxista para se pensar e fazer a História da Psicologia (ANTUNES, 2005; BUSS, 1979; LACERDA JR., 2018), não é fácil encontrar estudos historiográficos orientados pelo marxismo. Por isso, pensamos que seria interessante explorar e sistematizar como o marxismo foi apropriado por pesquisadoras e pesquisadores da História da Psicologia.

Assim, tendo em vista as possíveis contribuições do Marxismo para a História da Psicologia, o presente trabalho apresenta o resultado de uma pesquisa que explorou como o Marxismo foi apropriado por historiadoras e historiadores da Psicologia por meio de uma análise de artigos publicados na revista Mnemosine. O estudo buscou: (a) identificar que vertentes e autores do marxismo foram utilizados em trabalhos que se apropriaram da tradição marxista e (b) identificar como o marxismo tem sido utilizado pelos historiadores da Psicologia.

A opção pelo periódico Mnemosine, fundado em 2001, se deu por ser um dos dois únicos periódicos brasileiros dedicados à História da Psicologia ${ }^{2}$. Vale ressaltar que essas revistas não representam a totalidade dos escritos dedicados à área, já que na Psicologia brasileira há inúmeros periódicos que publicam artigos de História da Psicologia. Todavia, por se tratar de um periódico que explicitamente se dedica a receber produções historiográficas que são orientadas por correntes críticas da teoria social, julgamos que seria pertinente identificar se o pensamento clássico de Marx e marxistas é parte dos interesses investigativos de autoras e autores que se orientam por perspectivas críticas.

O levantamento foi realizado por meio da busca das palavras-chave "Marx", "marxismo", "marxista" e "materialismo" nos trabalhos publicados no periódico Mnemosine. Considerando o baixo número de resultados, optou-se por buscar os termos no trabalho como 
um todo e não apenas nos títulos ou resumos. A pesquisa foi realizada em setembro de $2016 \mathrm{e}$ abrange artigos publicados entre 2004 e 2016.

\section{Resultados da pesquisa}

Foram encontradas 51 publicações de um total de 317 textos publicados até setembro de 2016, representando $15,77 \%$ do total de trabalhos publicados no periódico até aquele momento. Desses, 24 trabalhos foram encontrados com a palavra "Marx"; 22 trabalhos com a palavra "marxismo"; 18 trabalhos com a palavra "marxista" e 14 trabalhos com a palavra “materialismo".

A partir do levantamento e após a leitura de títulos e resumos dos trabalhos, foram estabelecidos alguns critérios de exclusão:

1. Textos que não fossem artigos, o que resultou na exclusão de uma tese de doutorado e de quatro capítulos de um livro. Esse foi o caso do trabalho de Santos (2008) e dos capítulos de Lourau (2007).

2. Artigos que faziam referência a autores diferentes de Karl Marx, apesar de fazerem referência ao mesmo sobrenome. Este critério resultou na eliminação do artigo de Rocha e Pedro (2012).

3. Artigos que mencionavam um materialismo diferente do materialismo históricodialético de Marx. Esse critério resultou na eliminação de dois artigos: de Arendt e Costa (2005), por mencionarem "materialismo" para se referir à materialidade corporal; e de Larrauri (2014) ao se referir ao materialismo do discurso de Foucault.

Com a aplicação desses três critérios de exclusão, restaram 42 artigos para a análise. Esta foi dividida em duas partes. Na primeira etapa, foram analisados 34 artigos selecionados a partir de uma leitura flutuante e identificação das palavras-chave. Esses artigos abordam o marxismo de maneira muito geral, com contribuições limitadas e menções em partes específicas do texto. Deste modo, a menção ao marxismo se dá de forma isolada e não o apresenta como fundamento do trabalho, sem grandes contribuições para o presente estudo. Eles foram classificados em 5 categorias descritas a seguir (ver Tabela 1).

Na segunda análise, foram selecionados 9 artigos para uma análise mais aprofundada, que foram lidos integralmente e classificados em 3 categorias (ver Tabela 2). Estes trabalhos foram selecionados por meio de uma leitura flutuante e identificação das palavras-chave por apresentarem estudos de autores marxistas ou do próprio Marx, ultrapassando a generalidade 
verificada nos artigos da primeira análise. Nessa segunda análise, foram descritas as principais teses dos artigos e destacada a relação que se tem entre o trabalho e o marxismo.

\section{Artigos com menções gerais}

Foram identificados 34 artigos que mencionaram, de uma forma muito geral, a tradição marxista. A leitura possibilitou a classificação dos textos em cinco categorias que expressam como o marxismo foi mencionado no texto. É importante frisar, mais uma vez, que neste momento são textos que mencionam apenas pontualmente ou de forma extremamente geral o pensamento de Marx ou do marxismo.

Quadro 1 - Artigos com menções gerais

\begin{tabular}{|l|l|}
\hline \multicolumn{1}{|c|}{ Categoria } & \multicolumn{1}{|c|}{ Artigos encontrados } \\
\hline Marxismo como complemento & $\begin{array}{l}\text { Alberti (2004); Machado (2009); } \\
\text { Zamboni \& Barros (2012). }\end{array}$ \\
\hline Oposição ao marxismo & $\begin{array}{l}\text { Machado \& Banchetti (2009); Menezes } \\
(2011) ; \text { Ribeiro (2006) }\end{array}$ \\
\hline Marxismo como influência & $\begin{array}{l}\text { Baptista (2013); Cesse Neto \& Moraes } \\
(2011) ; \text { Cunha et alii. (2006); L'Abbate } \\
(2012) ; \text { Machado (2008); Melo (2009); } \\
\text { Mizoguchi (2015); Oliveira (2010); Penna } \\
(2004) ; \quad \text { Rodrigues (2008); Schroeder } \\
(2008) ; \text { Souza Jr. \& Cirino (2009) }\end{array}$ \\
\hline Interpretações marxistas & $\begin{array}{l}\text { Ferreira et alii. (2010); Fontes (2004); } \\
\text { Mattar (2012); Nascimento (2013); } \\
\text { Ramminger (2008) }\end{array}$ \\
\hline Outros & $\begin{array}{l}\text { Cerezzo (2005); Ferreira (2007); Heckert } \\
(2009) ; \text { Hur (2013); Macedo et alii. } \\
(2009) ; \text { Marino \& Baptista (2007); Mattos } \\
\& \text { Mattos (2015); Melo (2004); Moraes } \\
(2009) ; \quad \text { Rodrigues (2012); Zoungrana } \\
(2015) . \quad\end{array}$ \\
\hline
\end{tabular}




\section{i. Marxismo como complemento}

Nesta categoria, foram agrupados 3 trabalhos que utilizam contribuições pontuais de Marx para auxiliar alguma análise secundária. Alberti (2004) menciona Marx para afirmar que os conflitos sociais têm fundamento em relações econômicas. Machado (2009) cita um trecho de "O Capital” de Marx para demonstrar a mídia como produtora de desejos. Zamboni e Barros (2012) utilizam uma citação da mesma obra para comentar a negligência das organizações na relação dos humanos com as máquinas.

Nota-se, a partir das leituras, uma apropriação de teses marxistas com a finalidade de fortalecer análises historiográficas. Neste sentido, o marxismo seria uma caixa de ferramentas que pode ser usada para contribuir para teorias sociais críticas.

\section{ii. Oposição ao marxismo}

Alguns trabalhos mencionam o marxismo a fim de criticá-lo, sem fazer referência a qualquer autor ou obra marxista. Nos 3 artigos aqui agrupados, são apontadas possíveis limitações do marxismo que justificam sua negação. Em uma nota de rodapé, Machado e Banchetti (2009) citam um autor que estuda questões culturais para afirmar que estas foram subestimadas por Marx.

Menezes (2011) contrapõe a noção foucaultiana de história à de Marx e critica este por operar com uma causalidade única: as relações de produção. Ribeiro (2006) menciona o marxismo para criticar uma concepção que encara o conhecimento como reflexo da infraestrutura econômica. Também utiliza Horkheimer para mostrar conexões entre a filosofia e a história da modernidade, ainda que seja apenas para complementar análises que estão majoritariamente fundamentadas em Foucault e Deleuze.

\section{iii. Marxismo como influência}

Os 12 trabalhos agrupados nessa categoria mencionam o marxismo como influência de disciplina, escola, autor ou período histórico. Penna (2004) cita o marxismo como influência em uma aula de economia medieval. Cunha et alii. (2006) apresentam o marxismo como influência teórica da Análise Institucional. Machado (2008) menciona Pêcheux como representante da Psicologia Social influenciado pelo marxismo e pela psicanálise. Rodrigues (2008) destaca a influência do marxismo na trajetória de Lapassade e colaboradores, assim como parte do ambiente intelectual da época. 
Schroeder (2008) cita a influência do marxismo na trajetória pessoal e no contexto social de Roberto Freire. Melo (2009) menciona o marxismo como forte influência na vida de Nise da Silveira. Souza Jr. e Cirino (2009) salientam a forte influência do marxismo-leninismo na difusão da reflexologia soviética. Oliveira (2010) e L'Abbate (2012) citam como o marxismo influenciou, de diferentes maneiras, a obra de Lourau. Cesse Neto e Moraes (2011) apontam o marxismo como uma influência de Reich. Baptista (2013) comenta a influência que o próprio autor teve de autores marxistas. Mizoguchi (2015) cita dois conceitos de Blanchot que tiveram influência marxista e spinozista.

De fato, nesta categoria não há uma análise sobre a concepção de história marxista, mas apenas constatações da influência de Marx sobre a trajetória de acadêmicos, pesquisadores, intelectuais ou escolas de pensamento.

\section{iv. Interpretações marxistas}

Nesta categoria foram agrupados trabalhos que mencionam leituras marxistas de variados fenômenos. Fontes (2004) menciona Marx como exemplo característico de um momento histórico em que pulularam teorias centradas em conflitos. Ramminger (2008) destaca o marxismo como um tipo de análise histórica sobre a saúde pública que foca a relação entre Estado, estruturas econômicas, sociais, políticas e as instituições de saúde.

Ferreira et alii. (2010) citam como Basaglia apresentou uma leitura marxista do campo da saúde mental ao compreender a loucura como fruto das contradições do capitalismo e defender a mudança radical das instituições. Mattar (2012) cita Marx como autor que concebia a filosofia como atividade concreta e como maneira de mudar a percepção do mundo. Nascimento (2013) ressalta a importância do materialismo histórico para a transformação da Psicologia Social brasileira, voltando-se para classes menos favorecidas.

Nesta categoria identificamos trabalhos que dão sinais de possíveis contribuições da tradição marxista para a pesquisa historiográfica (a possibilidade de explorar conflitos sociais, incluir os processos sociais na análise histórica, pensar a historicidade dos processos ou fenômenos psicológicos, etc.); contudo, são menções superficiais que não exploram as possibilidades indicadas.

\section{v. Outros}


Nessa categoria foram incluídos 10 trabalhos que fazem menções a Marx ou ao marxismo bastante pontuais e que não foram agrupados nas categorias anteriores.

Em Melo (2004), há uma referência que tem em seu título o nome de Marx e que é utilizada para uma citação literal sobre Ulysses Pernambucano. Cerezzo (2005) cita Marx para realçar um argumento relacionado com seu estudo sobre a noção foucaultiana de autoria e obra.

Ferreira (2007) menciona que Antônio Gomes Penna tinha leituras de Marx, mas era mais próximo da democracia liberal. Marino e Baptista (2007) citam um autor que utiliza Marx como exemplo de uma mudança na concepção de homem. Heckert (2009) lista Marx como um dos autores que tomam o trabalho como categoria de análise. Uma das entrevistadas no trabalho de Macedo et alii. (2009) cita alguns professores marxistas que participaram da construção da disciplina de Psicologia em uma instituição do Piauí.

Moraes (2009) utiliza uma nota de rodapé que faz menção a uma referência que tem "marxismo" em seu título para tratar sobre tradição seletiva na arte. Rodrigues (2012) comenta a admiração de Maugüé por Marx e Freud. Hur (2013) salienta a emergência de grupos guerrilheiros marxista-leninistas a partir da segunda metade da década de 1960 no Brasil. Mattos e Mattos (2015) citam o marxismo como influência na vida de um dos entrevistados. Em Zoungrana (2015), o marxismo é utilizado como exemplo do pensamento hegemônico da época da produção de Foucault.

\section{vi. Considerações parciais sobre a primeira análise}

Em síntese, nos artigos que abordam o marxismo de forma geral, nenhum utiliza a concepção de história de Marx para fundamentar seus estudos. A ausência de referência a autores marxistas é predominante e, nos casos em que há citações, são de referências de comentadores. Vale ressaltar a quantidade de trabalhos analisados nessa etapa (34), apontando para o fato de que apesar de o levantamento ter encontrado Marx ou o marxismo em mais de 15\% das publicações da revista Mnemosine, o fato é que apenas um número muito reduzido utilizou de fato a tradição marxista em sua fundamentação teórica. Estes serão tratados a seguir.

\section{Artigos que tratam do marxismo}

A seguir são apresentados os nove trabalhos que analisaram, de alguma forma, contribuições da tradição marxista. Da mesma forma como a primeira etapa de análise, os 
artigos encontrados foram agrupados em categorias e analisados. A seguir apresentamos os resultados da segunda análise da pesquisa.

Quadro 2 - Artigos que tratam do marxismo

\begin{tabular}{|l|l|}
\hline Categoria & Artigos encontrados \\
\hline Oposição ao marxismo & Chevallier (2015); Vasconcelos, (2005) \\
\hline $\begin{array}{l}\text { Marxismo como fundamento de uma } \\
\text { escola ou autor }\end{array}$ & $\begin{array}{l}\text { Hazin et alii. (2010); Perucchi (2008); } \\
\text { Rezende et alii. (2013) }\end{array}$ \\
\hline $\begin{array}{l}\text { Crítica marxista de processos } \\
\text { psicossociais }\end{array}$ & $\begin{array}{l}\text { Blume (2009); A. M. T. Carvalho (2010; } \\
\text { 2011); P. R. Carvalho, (2009) }\end{array}$ \\
\hline
\end{tabular}

\section{i. Oposição ao marxismo}

Nesta categoria, foram agrupados os trabalhos de Vasconcelos (2005) e Chevallier (2015) que buscaram apontar limitações do marxismo. Em Vasconcelos (2005), há uma defesa da necessidade de se complementar o marxismo com outras teorias do inconsciente. Já Chevallier (2015) argumenta que há limitações para a definição da história a partir do marxismo e apresenta uma concepção distinta. A seguir serão expostas as principais ideias de ambos os textos.

O trabalho de Vasconcelos (2005) objetiva apontar limites e contribuições de Marx para uma teoria da subjetividade. $\mathrm{O}$ autor aponta alguns elementos sobre as raízes do pensamento marxista e argumenta que Marx contribuiu para demonstrar a primazia das relações históricas e sociais na constituição da subjetividade. Entretanto, ainda segundo o autor, existem limitações na compreensão marxista da dinâmica e das especificidades do psiquismo humano: em especial, a crença de Marx em uma possibilidade de homem completo a partir da superação da luta de classes, subestimando o inconsciente, uma vez que se vislumbra a satisfação total do desejo humano. Há, também, uma reafirmação implícita do romantismo em Marx, que acreditaria que o homem é essencialmente bom (VASCONCELOS, 2005).

Vasconcelos (2005) também argumenta que a negligência de Marx e Engels às questões subjetivas teve consequências históricas negativas $\mathrm{O}$ surgimento da psiquiatria e da psicologia reflexológicas e sua utilização para fins totalitários seriam exemplos de tais consequências. Além disso, o autor afirma que ainda hoje não existe uma teoria estritamente marxista que trate a subjetividade de forma satisfatória. Para isso, contribuições de teorias psicológicas ao 
marxismo são necessárias para uma compreensão mais acurada do ser humano em sua totalidade.

Já Chevallier (2015) expõe a concepção de história das problematizações de Foucault em contraposição a outros dois modelos de historiografia: a história das mentalidades e a história das representações. Esta seria a concepção da historiografia marxista, pois as ideias utilizadas para pensar o mundo são julgadas de acordo com critérios objetivos. A ideologia seria uma construção intelectual que justifica ações da classe dominante, ocultando suas motivações materiais e as lutas sociais. Ainda segundo Chevallier (2015), Foucault superaria a concepção marxista de espírito como o reflexo de uma situação concreta, ao conceber a atividade do sujeito com finalidade essencialmente crítica, sendo irredutível ao seu contexto político e social.

Nos dois trabalhos, há críticas ao marxismo. Vasconcelos (2005) se refere àquele para salientar suas limitações, especialmente sua negligência às questões subjetivas, micropolíticas e certo romantismo que acredita em uma conciliação entre desejo e processos sociais. Assim, sua ênfase é na proposta de adoção de teorias psicológicas como complemento ao marxismo para suprir suas limitações. Já Chevallier (2015) aborda o marxismo criticando sua concepção de história a partir de Foucault. Entretanto, o autor realiza uma diferenciação entre "marxista" e "marxiana", na qual não necessariamente uma história "marxiana" incorreria nos problemas que fazem Foucault se opor ao marxismo. Assim, na historiografia com bases marxistas (história das ideologias), o domínio do espírito não está separado de suas determinações sociais, mas a relação que se estabelece entre eles é simples e imprecisa. O espírito, nessa vertente, é tido como um reflexo ou tradução de uma situação concreta. Não há, ao contrário de Foucault, uma concepção de homem livre, reflexivo e crítico.

Em síntese, ambos os trabalhos apontam limitações do marxismo. Vasconcelos (2015) defende a necessidade de se complementar o marxismo com outras teorias do inconsciente para que suas limitações relativas à subjetividade sejam suprimidas. Já Chevallier (2015) aponta limitações do marxismo como fundamento para a proposição de Foucault sobre a história. Segundo esse trabalho, a história marxista prevê uma relação linear e mecânica entre situações concretas e o indivíduo.

\section{ii. Marxismo como fundamento de uma escola ou autor}

Nesta categoria foram agrupados os trabalhos de Perucchi (2008), Hazin et alii. (2010) e Rezende et alii. (2013) por terem destacado o marxismo como fundamento de uma escola de 
pensamento ou da produção de determinado autor. Assim, o trabalho de Perucchi (2008), em uma análise sobre as diferentes perspectivas da Análise do Discurso, destaca como o marxismo era, na década de 1960, quando emerge a escola de Análise do Discurso Francesa, um fundamento importante para autores que buscavam estabelecer as bases materiais da linguagem. O marxismo também é apresentado como uma influência na Inglaterra, com a Análise Crítica do Discurso. O termo é usado por autores influenciados por marxistas como Gramsci e Bakhtin e que enfatizam a correlação entre linguagem e contextos sociais.

Hazin et alii. (2010) discutem as contribuições da neuropsicologia de Luria ao debate sobre relações entre mente e cérebro. Para isso, destacam Luria como um dos principais representantes da Psicologia Histórico-Cultural, surgida no século XX na Rússia. Assim, a influência do marxismo aparece de diferentes maneiras: (1) como pressuposto que guia as análises sobre a relação entre processos naturais e culturais; (2) como influência políticoideológica resultante da Revolução Russa, sofrendo mudanças de acordo com as lutas políticas que ocorreram no país, especialmente a hegemonia do stalinismo (HAZIN et alii., 2010).

No trabalho de Rezende et alii. (2013) há uma elaboração sobre a possibilidade de relação entre o intelectual marxista Georges Politzer e Lev S. Vigotski, sobretudo pelo conceito de atividade. Os autores traçam elementos comuns entre Vigotski e Politzer que só existem pela herança marxista comum. Dentre eles destacam a crítica às tentativas de estudo de processos psicológicos elementares e a proposta de análise global da psique; a interpretação como método indireto de investigação. O ponto de convergência considerado mais importante é a adoção da atividade prática ou do ato concreto como unidade de análise da Psicologia (REZENDE et alii. 2013).

Nesta categoria vemos que as pesquisas abordam o pensamento marxista como influência de autores ou escolas que estão estudando. Neste sentido, não são trabalhos sobre Marx ou o marxismo, mas pesquisas históricas que os identificam como influências teóricas.

Perucchi (2008), por exemplo, busca identificar autores que utilizam o marxismo como base para a produção de seus estudos. Por exemplo, Pêcheux é citado como autor influenciado por Althusser, enquanto Bakhtin e Gramsci são citados como influências da escola inglesa da Análise Crítica do Discurso. Esses marxistas utilizam o conceito de ideologia em detrimento do conceito de poder.

No trabalho de Rezende et alii. (2013), o marxismo é mencionado como fundamento das produções de dois autores em momentos análogos: Vigotski (na Rússia) e Politzer (na 
França). São realizadas referências a trabalhos de Marx e outros autores marxistas. Além disso, existem menções ao marxismo como forte influência do período pós-Revolução Russa, consequentemente exercendo forte influência nas produções dos autores analisados.

Por fim, no trabalho de Hazin et alii. (2010), o marxismo é citado diretamente ao comentar a crítica que muitos fazem a Luria e Leontiev por terem traído Vigotski e a psicologia histórico-cultural ao cederem às pressões do governo russo e aos pilares da Revolução Russa. Também há uma referência direta ao marxismo ao comentar a proibição que o governo russo fez à agenda de pesquisa da Psicologia Histórico-Cultural, o que levou à dissolução da Troika em nome dos ideais marxistas. Há, também, uma menção ao materialismo histórico ao apontálo como fundamento da Psicologia que Luria, Leontiev e Vigotski buscaram desenvolver.

Em resumo, os três trabalhos citam o marxismo para apontar produções realizadas a partir dele. Em Perucchi (2008), apesar de haver crítica à escola da Análise Crítica do Discurso, o foco do trabalho é demonstrar como o marxismo fez parte de suas bases teóricas. Em Rezende et alii. (2013) e Hazin et alii. (2010), o marxismo aparece como fundamento para a produção de Politzer, Vigotski e Luria. Vale ressaltar que os três trabalhos também apontam que a forte influência do marxismo foi resultado de um período histórico específico, sobretudo após a Revolução Russa de 1917.

\section{iii. Crítica marxista de processos psicossociais}

Esta categoria reúne trabalhos que utilizam o marxismo como um dos instrumentos teóricos utilizados para compreender e criticar processos psicossociais. Os trabalhos de Blume (2009), P. R. Carvalho (2009) e A. M. T. Carvalho (2010; 2011) utilizam leituras marxistas para analisar processos psicossociais como parte de sua análise.

No artigo de Blume (2009), há uma discussão sobre os processos sociais de luta cotidiana para a manutenção de modos de trabalho tradicionais a partir de narrativas orais de marisqueiras e pescadores artesanais na cidade de Ilhéus (BA). Para isso, o autor utiliza-se do campo da História Oral por dar visibilidade às histórias e memórias de grupos subalternos e inexistentes na História. O autor destaca a importância de se levar em conta os conflitos de classes e comprometer-se com as demandas e lutas dos sujeitos de sua investigação.

Em P. R. Carvalho (2009) há uma discussão sobre a influência do capitalismo na construção da sexualidade contemporânea. Para o autor, a partir de Guattari, na sociedade capitalista, as subjetividades são produzidas e reproduzidas sob a hegemonia dos valores 
associados ao capital. Elas são produzidas de forma serializada e empobrecida, implicando em perda da possibilidade de maior variação subjetiva e singular. Marx aparece na análise sobre como o desejo produzido tem como objeto mercadorias descartáveis, isto é, os humanos assumem características de mercadoria e a própria mercadoria passa a exercer controle sobre os humanos (o que Marx chama de "fetiche da mercadoria").

A. M. T. Carvalho (2010) discute a história da Higiene Mental no Brasil por meio do primeiro artigo publicado nos "Archivos Brasileiros de Hygiene Mental" (ABHM) de Carlos Penafiel. Para isso, o autor afirma que conta com influências do materialismo histórico-dialético e da arqueologia do poder, trabalhando com as convergências de diferentes linhas teóricas. Apoiado em Guattari, o autor defende a tese de que o processo de produção de subjetividades tem como objetivo a produção de indivíduos normalizados, articulados uns aos outros e hierarquizados. O autor também afirma, baseado em Marx e Mészáros, que o discurso da revista ABHM se colocava a serviço da elite e das forças do Capital, sem fazer distinção entre a forma ontológica e histórica do trabalho, além de negar a existência do conflito de classes.

Em outro trabalho, A. M. T. Carvalho (2011) realiza um apanhado histórico das produções discursivas no campo da saúde mental no trabalho. $\mathrm{O}$ autor defende que o entendimento do discurso só é possível no interior das relações sociais de produção; assim, a categoria trabalho no texto do autor é tomada em uma perspectiva ontológica. A precarização do trabalho verificada atualmente é um dos sinais mais expoentes da crise estrutural do capital. O autor destaca como, fortemente influenciados pelo materialismo dialético, psicólogos sociais começaram a buscar uma ciência comprometida com a transformação social, recorrendo a categorias como alienação, trabalho concreto e abstrato. Com isso, o sofrimento pôde ser analisado pelo materialismo dialético de forma a demarcar o comprometimento com a classe trabalhadora (CARVALHO, 2011).

Nesta categoria apresentamos trabalhos que utilizam de forma mais extensiva de teses e autores marxistas. Por exemplo, no trabalho de Blume (2009), o marxismo aparece por meio do recurso à obra de Bakhtin para discussões teórico-metodológicas e análises de dados, assim como utiliza-se de autores marxistas e categorias como "classes sociais".

No trabalho de P. R. Carvalho (2009), o marxismo é mediado por comentadores. Sua crítica dos processos societários no Capital se deve às leituras de Guattari, Rolnik e Carone. Esta última, uma estudiosa da Escola de Frankfurt, é utilizada para destacar a centralidade do 
"fetiche da mercadoria" na vida humana atual: a mercadoria condiciona as subjetividades de sociedades capitalistas, empobrecendo-as e resultando no abandono de potencialidades.

O marxismo é utilizado nos artigos de A. M. T. Carvalho $(2010 ; 2011)$ como recurso crítico de ideias psicológicas no Brasil. Em um trabalho, Marx e Mészáros aparecem ao lado de Guattari e Foucault para se criticar a ideologia higienista da produção de Penafiel e, assim, problematizar o capitalismo (A. M. T. Carvalho, 2010).

Já no segundo trabalho (A. M. T. Carvalho, 2011), o marxismo é utilizado de forma ampla a fim de buscar leituras do campo da saúde mental do trabalho que sejam compromissadas com a classe trabalhadora. Ele utiliza autores marxistas como Lukács, Ianni e até o próprio Marx, juntamente com Deleuze, Dejours e Foucault, para expor questões econômicas e sociais mais amplas que influenciaram as produções que analisa. Ademais, é referenciado como fundamento de psicólogos sociais que produziram conhecimentos compromissados com uma transformação social. Ao longo de todo o trabalho de A. M. T. Carvalho (2011), o autor ressalta a importância de conhecimentos que sejam compromissados com a classe trabalhadora, além de defender uma concepção ontológica de trabalho e citar categorias caras à tradição marxista, tais como trabalho concreto, trabalho abstrato, classe social, reificação e alienação.

Em suma, os quatro artigos agrupados nessa categoria utilizam o marxismo para complementar sua análise por meio da crítica de determinados processos sociais realizada por essa tradição teórica. Em Blume (2009), há a utilização de teses marxistas para a análise de processos sociais mais amplos pelos quais se produzem os discursos que analisa. P. R. Carvalho (2009) utiliza o marxismo por uma comentadora a fim de demonstrar o impacto da mercadoria na subjetividade e, consequentemente, na sexualidade. Os trabalhos de A. M. T. Carvalho (2010; 2011) utilizam o marxismo de forma mais ampla; entretanto, o autor não parte de uma concepção marxista de história para fundamentar seu trabalho. Há, também, uma mescla de autores de diferentes correntes teóricas para a produção de sua análise.

\section{Considerações finais}

O presente trabalho objetivou explorar como a concepção marxista de história foi apropriada por historiadoras e historiadores da Psicologia por meio de uma análise de artigos publicados na revista Mnemosine. Após a análise realizada, constatou-se que os trabalhos publicados não realizaram investigações históricas guiadas pela concepção de história dessa 
tradição teórica. O que foi possível identificar foi a existência de trabalhos que: (a) apresentaram críticas à concepção marxista de história; (b) realizaram pesquisas históricas e, no percurso delas, identificaram o marxismo como base teórica de autores, obras, publicações, escolas de pensamento etc.; (c) trabalhos que analisaram processos sociais ou psicossociais combinando múltiplos referenciais teóricos, dentre eles a tradição marxista.

Nos artigos analisados na primeira etapa do trabalho, parte essa que agrupa a maioria dos trabalhos analisados, foi perceptível a generalidade com a qual o pensamento marxista foi apropriado. Já na segunda etapa, os poucos trabalhos que utilizam contribuições marxistas sistematicamente não realizaram pesquisas históricas a partir do método de Marx. Assim, não existem estudos neste periódico que buscam retirar elementos do marxismo para se pensar modos de se fazer e pensar a História da Psicologia, tal qual Antunes (2005), Buss (1979) e outros defendem. Isto parece indicar que no periódico Mnemosine, a tradição marxista tem uma presença residual. Cabe investigar se, em outros periódicos e investigações na História da Psicologia, o mesmo padrão se repete.

Especificamente, o estudo buscou identificar as vertentes do marxismo utilizadas nesses trabalhos e como as publicações utilizaram contribuições marxistas. Foi possível perceber que o marxismo é predominantemente utilizado: (a) como complemento a uma análise realizada; (b) como uma tradição teórica que deve ser criticada; (c) como influência de um autor, escola ou período histórico; (d) como uma possibilidade hermenêutica. Entre os autores utilizados, percebemos a raridade do recurso ao pensamento de Marx e Engels. Quase sempre as obras recorriam aos trabalhos de comentadores ou de intérpretes importantes.

Tais resultados são importantes para observar o próprio periódico Mnemosine. Trata-se de um periódico aberto a vertentes críticas da teoria social e a ínfima presença da tradição marxista em suas publicações pode ser um indicador do próprio eclipse do Marxismo que ocorreu no fim do século XX.

Em síntese, o presente levantamento revelou que, apesar de uma quantidade significativa mencionar o pensamento de Marx, boa parte dos trabalhos se resume a identificar a presença ou a influência da tradição marxista na história da Psicologia. São trabalhos importantes, pois possibilitam identificar a presença do Marxismo na obra de um autor, em uma escola de pensamento ou em uma certa instituição.

Também percebemos que existe certa quantidade de trabalhos que, de forma mais geral e sumária (ver: Machado \& Banchetti, 2009; Menezes, 2011; Ribeiro, 2006), ou de forma mais 
aprofundada (ver: Chevallier, 2015; Vasconcelos, 2005) apresentaram críticas à concepção marxista de história. De um lado, há as críticas que afirmam que a concepção marxista de história é monocausal ou é marcada por um determinismo econômico em que esta conforma uma base que determina linearmente processos superestruturais, como a consciência ou a cultura.

Estas são críticas que consideramos unilaterais ou equivocadas. Podem estar corretas ao abordar certas correntes da tradição marxista, mas definitivamente não são corretas se considerarmos o pensamento de Marx. Em primeiro lugar, porque as relações de produção não são tomadas como causalidade única por Marx. Para o autor, as causas do movimento e das mudanças históricas são frutos da relação entre diferentes complexos que são sínteses de múltiplas determinações. Em suas palavras: "O concreto é concreto porque é a síntese de muitas determinações, isto é, unidade do diverso" (Marx, 1857/1982: 14).

Da mesma forma, Netto (2011) e antropólogos como Wolf (1984) ou historiadores como Hobsbawm (2013) destacam que a tese de que a superestrutura é um epifenômeno em relação à base econômica foi defendida apenas por vulgatas e simplificações do pensamento marxiano, o qual é marcado pelo cuidado em considerar a reciprocidade das determinações na relação entre base e superestrutura, assim como afirmou explicitamente que a cultura ou mesmo o sujeito individual são agentes centrais na mudança da base econômica.

Por outro lado, as críticas que defendem a tese de que o pensamento marxiano é incapaz de contribuir para o estudo da subjetividade (Vasconcelos, 2005) ou carece de uma concepção de ser humano como sujeito livre (Chevallier, 2015) também parecem ser demasiado arbitrárias. Em primeiro lugar, neste levantamento encontramos diversos textos, citados anteriormente, que apontaram para como a tradição marxista trouxe contribuições, dentre diversos exemplos, para o campo da saúde mental ou para o surgimento de teorias de base marxistas. Também ignoram trabalhos de inúmeros autores dentro e fora da Psicologia.

Desde a Psicologia, podemos citar: Klaus Holzkamp (1985/1991), que, a partir da teoria marxiana, elaborou uma "teoria desde a perspectiva do sujeito" em favor da ampliação da liberdade individual pela transformação das condições sociais; Carl Ratner (2017) ou Silvana Tuleski (2002), que estão fazendo inúmeras propostas sobre a construção de uma Psicologia Marxista. Fora da Psicologia, apenas no Brasil, diferentes autores vêm apontando que a principal contribuição de Marx foi, justamente, apresentar uma concepção de ser humano que possibilita pensar as condições e possibilidades históricas de uma individualidade ou 
personalidade livre e autodeterminada (ver, por exemplo: COSTA, 2007; GUERRA \& JIMENEZ, 2016).

A partir do exposto, podemos apresentar a hipótese de que a inexistência de pesquisas historiográficas em Psicologia guiadas pela concepção marxista de história está relacionada com a inexistência da apropriação do pensamento de Marx (o que é indicado pela rara menção ao pensamento do clássico) e com o predomínio de uma postura sectária em relação à tradição marxista. Tudo isso indica que a incorporação do pensamento marxista para contribuir no desenvolvimento de pesquisas críticas no âmbito da História da Psicologia é, ainda, uma atividade marginal no campo.

Tal marginalidade pode ser compreendida por diversos fatores. As perspectivas pósestruturalistas e pós-modernas presentes na maioria dos trabalhos que se pretendem críticos no campo ganharam corpo justamente após o fim da década de 1960, período caracterizado pela falência das tentativas de socialismo e "crise" da tradição marxista (ANDERSON, 2019). De mesmo modo, o engessamento de parte do marxismo para legitimar e justificar o stalinismo ainda é utilizado como referência de uma tradição que não é uníssona.

Além disso, sua capacidade explicativa em consonância com as estruturas capitalistas vigentes são um importante fator para sua difusão. Leituras que negam um processo histórico geral, meta-narrativas ou a própria concepção de verdade não são capazes de compreender e ameaçar uma sociedade dividida em classes. Ademais, Wood (1996) ressaltou como essas proposições têm estreita relação com o momento histórico e social no qual foram gestadas, marcadas por um "capitalismo global, segmentado, consumista e móvel" (p. 125).

\section{Referências}

ALBERTI, Sonia. História da psicologia no Brasil - origens nacionais. Mnemosine, vol. 1, n ${ }^{\circ}$ $0,2004$.

ANDERSON, P. Nas trilhas do materialismo histórico (Trad. F. Fernandes). Em: ANDERSON, P., Considerações sobre o marxismo ocidental / nas trilhas do materialismo histórico. São Paulo: Boitempo, 2019.

ANTUNES, Mitsuko Aparecida Makino. Materialismo histórico-dialético: fundamentos para a pesquisa em história da psicologia. Em: ABRANTES, Ângelo Antônio; SILVA, Nilma Renildes; MARTINS, Sueli Terezinha Ferreira. (Orgs.), Método histórico-social na psicologia social. Petrópolis: Vozes, 2005. 
ARENDT, Ronald João Jacques; COSTA, Carlos Alberto Marconi da. O corpo como fe(i)tiche - Possíveis contribuições do pensamento de Bruno Latour para a Psicologia. Mnemosine, vol. 1, n 2, 2005.

BAPTISTA, Luís Antônio dos Santos. Demolições da memória de um Psicólogo Anônimo: a invasão no cotidiano por flechas do Vietnam. Mnemosine, vol. 9, $\mathrm{n}^{\circ}$ 2, 2013.

BLUME, Luiz Henrique dos Santos. Memória popular: dialogando com narrativas orais de pescadores e marisqueiras de Ilhéus, BA, 1960-2008. Mnemosine, vol. 5, nº 2, 2009.

BUSS, A. A dialectical psychology. New York: John Wiley \& Sons, 1979.

CARVALHO, Alexandre Magno Teixeira de. Da Higiene Mental do Trabalho à Saúde Mental do Trabalhador: uma leitura da produção discursiva no Brasil (1925-1995). Mnemosine, vol. $7, \mathrm{n}^{\mathrm{o}} 2,2011$.

CARVALHO, Alexandre Magno Teixeira de. Higiene mental, eugenia e "elemento psychico" no trabalho humano: texto e contexto. Mnemosine, vol. 6, n 2, 2010.

CARVALHO, Paulo Roberto de. Subjetividade capitalística e sexualidade contemporânea: construindo um sentido. Mnemosine, vol. 5, nº 2, 2009.

CEREZZO, Antônio Carlos. Bourbaki e Jabin: análise de discurso em atos de vidas. Mnemosine, vol. 1, $\mathrm{n}^{\mathrm{o}}$ 2, 2005.

CESSE NETO, João da Mata R.; MORAES, Marcia. A capoeira angolana: corpo e resistência. Mnemosine, vol. 7, $\mathrm{n}^{\mathrm{o}}$ 2, 2011.

CHEVALLIER, Philippe. Que quer dizer fazer uma história das problematizações? Mnemosine, vol. $11, \mathrm{n}^{\circ} 2,2015$.

COSTA, G. M. Indivíduo e sociedade: sobre a teoria de personalidade em Georg Lukács. Maceió: EDUFAL, 2007.

CUNHA, Aline de Araújo Gonçalves da; DORNA, Lívia Borges Hoffmann; RODRIGUES, Heliana de Barros Conde. Uma contribuição à história da Análise Institucional no Brasil através de depoimentos orais: o Setor de Psicologia Social da Universidade Federal de Minas Gerais (UFMG) nas décadas de 1960 e 1970. Mnemosine, vol. 2, nº 1, 2006.

FERREIRA, Arthur Arruda Leal. Antônio Gomes Penna: estudante incondicional, cartógrafo e olheiro (ou como se contagiar com um desejo profuso). Mnemosine, vol. 3, no 1, 2007.

FERREIRA, Arthur Arruda Leal; PADILHA, Karina Lopes; STAROSKY, Miriam. A questão da cidadania e da liberdade nos processos da reforma psiquiátrica: novas possíveis práticas de governamentalidade. Mnemosine, vol. 6, nº 2, 2010.

FONTES, Virgínia. Clio e psyché - à procura de novos futuros. Mnemosine, vol. 1, nº 0, 2004.

GUERRA, B. M. de M.; JIMENEZ, S. V. Tornar-se indivíduo: bases ontológicas e processo histórico. Sobral: Edições UVA, 2016.

HAZIN, Izabel; LEITÃO, Selma; GARCIA, Danielle; LEMOS, Caroline; GOMES, Ediana. Contribuições da Neuropsicologia de Alexsandr Romanovich Luria para o debate contemporâneo sobre relações mente-cérebro. Mnemosine, vol. 6, nº 1, 2010.

HECKERT, Ana Lucia Coelho. Entre risos e narrativas: ver-Beth Barros. Mnemosine, vol. 5, $\mathrm{n}^{\circ} 1,2009$. 
HOBSBAWM, E. Sobre história. São Paulo: Companhia das Letras, 2013.

HOLZKAMP, Klaus. Societal and individual life processes. In: TOLMAN, Charles W.; MAIERS, Wolfgang (org.). Critical psychology: Contributions to an historical science of the subject. Cambridge: Cambridge University Press, 1985/1991.

HUR, Domenico Uhng. Cartografias da luta armada: a guerrilha como máquina de guerra. Mnemosine, vol. 8, $\mathrm{n}^{\circ}$ 2, 2012.

L'ABBATE, Solange. Análise Institucional e Intervenção: breve referência à gênese social e histórica de uma articulação e sua aplicação na Saúde Coletiva. Mnemosine, vol. 8, $\mathrm{n}^{\circ}$ $1,2012$.

LACERDA JR., F. Totalidade, individualidade social e ideologia: três contribuições da tradição marxista à História da Psicologia. In: JACÓ-VILELA, A.M.; OLIVEIRA, D.M. (Orgs.), Clio-Psyché: discursos e práticas na história da psicologia. Rio de Janeiro: EDUERJ, 2018.

LARRAURI, Maite. Verdade e mentira dos jogos de verdade. Mnemosine, vol. 10, no 2, 2014.

LESSA, Sérgio. Lukács: El método y su fundamento ontológico. Em: BORGIANNI, Elisabete; MONTAÑO, Carlos (Orgs.), Metodología y servicio social hoy en debate. São Paulo: Cortez, 2000.

LOURAU, René. René Lourau na UERJ - Análise Institucional e Práticas de Pesquisa. Rio de Janeiro: UERJ, 2007.

LUKÁCS, György. Para uma ontologia do ser social I (Trad. C. N. Coutinho, M. Duayer e N. Schneider). São Paulo: Boitempo, 1976/2012.

MACEDO, João Paulo; FERNANDES, Ana Gabriela Nunes; ARAÚJO, Renata Castelo Branco. A Psicologia e o ensino normalista piauiense: percursos de uma disciplina. Mnemosine, vol. 5, $\mathrm{n}^{\circ}$ 2, 2009.

MACHADO, Felipe Morelli; BANCHETTI, Luciano Deppa. Nas arquibancadas e nas tribunas! O binômio futebol/política na vivência dos estádios durante o governo Vargas: Pacaembu e São Januário. Mnemosine, vol. 5, nº 2, 2009.

MACHADO, Leila Domingues. Mídia, imagem e subjetividade. Mnemosine, vol. 5, nº 1, 2009.

MACHADO, Marília Novais da Mata. Análise do Discurso e Psicologia Social: um vínculo esquecido. Mnemosine, vol. 4, nº 2, 2008.

MARINO, Adriana Simões; BAPTISTA, Marisa Todescan Dias da Silva. A história como paradigma na construção de sujeitos de direitos. Mnemosine, vol. 3, nº 2, 2007.

MARX, Karl. Introdução à crítica da economia política. Trad. E. Malagodi e J. A. Giannotti. Em: MARX, Karl. Para a crítica da economia política: salário, preço e lucro - o rendimento e suas fontes. São Paulo: Abril Cultural, 1982 [1857].

MARX, Karl; ENGELS, Frederich. A ideologia alemã. Trad. R. Enderle, N. Schneider e L. C. Martorano. São Paulo: Boitempo, 1846/2007.

MATTAR, Cristine Monteiro. A fala do entrevistado como narrativa: encontros possíveis entre o psicólogo e a história oral a partir das contribuições de Alessandro Portelli. Mnemosine, vol. 4, nº 1, 2008. 
MATTAR, Cristine Monteiro. Escrita kierkegaardiana e a noção de cuidado de si. Mnemosine, vol. $8, \mathrm{n}^{\mathrm{o}} 1,2012$.

MATTOS, Beatriz da Silva; MATTOS, Amana Rocha. A subjetivação política de jovens: um estudo de caso. Mnemosine, vol. 11, no 2, 2015.

MELO, Walter. Nise da Silveira e o campo da Saúde Mental (1944-1952): contribuições, embates e transformações. Mnemosine, vol. 5, $\mathrm{n}^{\circ}$ 2, 2009.

MELO, Walter. Ulysses Pernambucano: o enamorado da liberdade. Mnemosine, vol. $1, \mathrm{n}^{\circ} 0$, 2004.

MIZOGUCHI, Danichi Hausen. Modulações da amizade: os conceitos e a produção do mundo. Mnemosine, vol. 11, $\mathrm{n}^{\circ} 1,2015$.

MORAES, Jonas Rodrigues de. A música de Luiz Gonzaga no território da "invenção das tradições". Mnemosine, vol. 5, nº 2, 2009.

NASCIMENTO, Aline Ribeiro. Ferramentas e ferrugem: apontamentos sobre o conceito de representação social. Mnemosine, vol. 9, n 2, 2013.

NETTO, José Paulo. Introdução ao estudo do método de Marx. São Paulo: Expressão Popular, 2011.

NETTO, José Paulo. O que é marxismo? São Paulo: Brasiliense, 1985.

OLIVEIRA, Sandra Raquel Santos de. Considerações sobre o método: ética e política como intensificação do pensamento. Mnemosine, vol. 6, $\mathrm{n}^{\circ}$ 2, 2010.

PENNA, Antônio Gomes. Minha caminhada na psicologia. Mnemosine, vol. 1, nº 0, 2004.

PERUCCHI, Juliana. Uma contextualização histórica das diferentes perspectivas da Análise do Discurso: configurações teórico-metodológicas pertinentes à Psicologia Social. Mnemosine, vol. 4, $\mathrm{n}^{\circ}$ 2, 2008.

RAMMINGER, Tatiana. Entre a normatividade e normalidade: contribuições de G. Canguilhem e M. Foucault para as práticas de saúde. Mnemosine, vol. 4, nº 2, 2008.

RATNER, C. Marxist psychology, Vygotsky's cultural psychology, and psychoanalysis: the double helix of science and politics. In: RATNER, C.; SILVA, D. N. H. (Orgs.), Vygotsky and Marx: Toward a Marxist Psychology. New York: Routledge, 2017.

REZENDE, Marcello Santos; ATHAYDE, Milton Raimundo Cidreira; CHRISTO, Cirlene de Souza. O conceito de atividade como unidade de análise na Psicologia? Um possível diálogo entre Vigotski e Politzer. Mnemosine, vol. 9, nº 1, 2013.

ROCHA, Iara de Salvo; PEDRO, Rosa. A Produção da paz na cidade do Rio de Janeiro. Mnemosine, vol. 8, n. 1, 2012.

RODRIGUES, Heliana de Barros Conde. Da importância de não ser filósofo - Um certo "Clima" e a docência de Jean Maugüé. Mnemosine, vol. 8, nº 1, 2012.

RODRIGUES, Heliana de Barros Conde. Encontro intempestivo: Georges Lapassade no Brasil, 1972. Mnemosine, vol. 4, nº 2, 2008.

SANTOS, Alessandra Daflon dos. "Rádice: muito prazer! Crônicas do passado e do futuro da Psicologia no Brasil". Mnemosine, vol. 4, nº 1, 2008. 
SCHROEDER, Vera. Corpo, Arte e Política - as contribuições de Roberto Freire para a Psicologia no Brasil. Mnemosine, vol. 4, nº 2, 2008.

SOUZA JÚNIOR, Eustáquio José de; CIRINO, Sérgio Dias. Revisando a reflexologia soviética. Mnemosine, vol. 5, $\mathrm{n}^{\circ}$ 2, 2009.

TULESKI, S. C. Vygotski: A construção de uma psicologia marxista. Maringá: Eduem, 2002.

VASCONCELOS, Eduardo Mourão. Românticos, exploradores do inconsciente e revolucionários: polêmicas históricas, desafios teóricos e suas implicações atuais. Mnemosine, vol. 1, n 2, 2005.

WOLF, Eric. Guerras camponesas do Século XX. Trad. I. Toledo. São Paulo: Global, 1984.

WOOD, Ellen M. Em defesa da História: o marxismo e a agenda pós-moderna. Crítica Marxista, v.1, n.3, 1996.

ZAMBONI, Jésio; BARROS, Maria Elizabeth de. Esquizoanálise da ergonomia: paradoxo do sistema homens-máquinas. Mnemosine, vol. 8, $\mathrm{n}^{\mathrm{o}}$ 2, 2012.

ZOUNGRANA, Jean. Epistéme. Mnemosine, vol. 11, $\mathrm{n}^{\circ}$ 1, 2015.

Lucas Matheus Pereira Cruvinel Pontifícia Universidade Católica de São Paulo - PUC-SP

E-mail: lucascruvine19@gmail.com

Fernando Lacerda Junior Universidade Federal de Goiás - UFG E-mail: fernando_lac@yahoo.com.br

\footnotetext{
${ }^{1} \mathrm{O}$ termo "marxiano" refere-se estritamente à produção de Karl Marx, diferente de termos como "marxista" ou "marxismo", adotados como sinônimos e que se referem a uma tradição de pensamento mais ampla e diversa.

${ }^{2}$ O outro periódico é Memorandum. Além desta, pode-se considerar a seção "Clio-Psyché" da Revista Estudos $e$ Pesquisas em Psicologia e periódicos internacionais. A investigação destas revistas pode dar maior suporte para as considerações apresentadas aqui, mas escapa ao estudo atual.
} 